\title{
Una lectura teológica de la realidad. ¿A cuáles nuevos saberes recurrir o con qué saberes contar?
}

\author{
Geraldo De Mori ${ }^{1}$ \\ FACULDADE JESUÍTA DE FILOSOFIA E TEOLOGIA \\ BELO HORIZONTE
}

La teología cristiana, en cuanto logos/palabra/discurso sobre Dios -que es un Dios que habla a los humanos-, no es un saber esotérico -reservado a una elite de iniciados-, o totalmente trascendente, sin nada que ver con la realidad. Al contrario, el Dios cristiano se revela en la historia y a la historia con sus «angustias, alegrías, sufrimientos y esperanzas» ${ }^{2}-\mathrm{y}$, por el misterio de la encarnación del Logos/Palabra/Hijo, asume las vicisitudes, posibilidades y límites de esta misma historia, acompañándola, dándole sentido, salvándola. Por lo tanto, nada de lo que forma parte de la realidad finita, mundana y humana es extraño o extranjero a Dios $y$, consecuentemente, al discurso de la teología. Todo lo que constituye nuestra finitud, mundanidad y humanidad puede, por eso, prestarse para una lectura teológica. Incluso más si se trata de la teología práctica, que hace de la praxis humana, en sus distintas dimensiones y significados, el objeto de su reflexión ${ }^{3}$.

1 Doctor en teología por Facultés Jésuites de Paris -Centre Sèvres-, profesor de antropología teológica y de escatología cristiana en la Faculdade Jesuíta de Filosofia e Teologia-FAJE-, Belo Horizonte, Brasil, donde es el Director del Departamento de Teología e Coordinador del Programa de Posgrado en teología. Publicó: A teologia em situação de pós-modernidade (São Leopoldo 2005); Le temps. Énigme des hommes, mystère de Dieu (Paris 2006); Teologia e Ciências da Religião. Rumo à maioridade acadêmica no Brasil (São Paulo 2011) (organizador junto con Eduardo Cruz).

2 Cf. Concilio Vaticano II, Gaudium et Spes, 1.

3 Sobre el significado de la praxis en teología, cf.: G. DE MORI, «El carácter práctico de la teología»; F. AQuino Júnior, «El carácter práxico de la teología: un enfoque epistemológico», Teología y vida LI (2010) 
El interés por todo lo que compone lo real o por la dimensión práxica del existir humano no lleva a la teología en general y a la teología práctica en particular a la elaboración de un saber alternativo al de las distintas ciencias, ni a un super-saber que las englobe a todas. En realidad, el saber teológico no ignora los demás saberes ni pretende substituirlos; los tiene en cuenta y se deja interpelar por ellos cuando capta el conjunto de la realidad a la luz de la revelación. Por eso, ya en sus inicios, en la patrística, la teología no menospreció los conocimientos antiguos (astronomía, matemáticas, filosofía, ética, visión del ser humano). Lo mismo sucedió en la Edad Media, con el surgimiento de nuevos saberes (alquimia, álgebra, astronomía, filosofía aristotélica, etc.). A partir del siglo XVI, a pesar de los conflictos entre la Iglesia Católica y varias interpretaciones de lo real elaboradas por el saber científico moderno y contemporáneo, que llevaron a la condenación de científicos y teólogos, la teología ya no puede ignorar lo que la física mecanicista, la teoría de la evolución, las ciencias humanas, la física relativista y cuántica, y los nuevos sistemas filosóficos propusieron como clave de lectura del cosmos, de la vida, de la historia y del actuar.

De hecho, las disciplinas que componen la teología, agrupadas en muchos currículos alrededor de la exégesis, de la sistemática y de la praxis, recorren de diversas formas a los saberes de varias ciencias en la elaboración de su propia reflexión. Las disciplinas de la exégesis, por ejemplo, utilizan estudios de historia, arqueología, lingüística, semiótica, narratología y retórica en los estudios correspondientes a los libros que componen la Biblia; las disciplinas de la sistemática toman en consideración las corrientes filosóficas modernas y contemporáneas, la historiografía, las teorías científicas sobre el cosmos y el ser humano, el psicoanálisis, la sociología, la genética, la etnología, las ciencias cognitivas, la crítica de las instituciones, la tanatología, la historia de las religiones, etc. En la reflexión sobre Dios, Jesucristo, la creación, la antropología, la Iglesia, la escatología; las disciplinas de la praxis, por su parte, acogen los resultados de los estudios de la fenomenología, psicología, sociología, economía, mística, pedagogía, retórica, de la salud y de la sexualidad, para los estudios sobre los sacramentos, la liturgia, la catequesis, la moral social y sexual, la bioética, la misionología, la organización pastoral, el acompañamiento espiritual, etc. 
La reflexión que proponemos no pretende abarcar toda la relación existente entre la teología y los saberes a los cueles ella recurre para elaborar su discurso. Se trata más bien, de una presentación panorámica del uso que la teología pastoral/práctica hace de los saberes de otras ciencias en la lectura teológica de la realidad y de las cuestiones que a partir de allí surgen para ella. Para esto iniciaremos con una retomada, de la historia de esta relación, mostrando, a seguir, las tendencias actuales para, finalmente, proponer lo que nos parece importante llevar en consideración en el recurso a otros saberes para pensar teológicamente la realidad que es objeto del quehacer teológico práctico/pastoral.

\section{El lugar de los otros saberes en la historia de la teología PRÁCTICA/PASTORAL}

A pesar de algunos esbozos de teología pastoral/práctica surgidos en el tiempo de la Reforma, el primer proyecto sistemático, en el mundo católico, se remonta a Stepan Rautenstrauch (1734-1785), y en el mundo protestante a Friedrich Schleiermacher (1768-1836), en el siglo XVIII iluminista ${ }^{4}$. La neoescolástica, por un lado, y la neoortodoxia, por otro, amenazaban entonces a que la fe cristiana y la teología se tornaran irrelevantes para la sociedad. Estos dos proyectos buscaron aproximar el quehacer teológico a la vida concreta de las iglesias y conferir cientificidad a la teología pastoral/práctica. Sin embargo, el énfasis que dieron al aspecto pragmático o técnico hizo que sus proyectos fueran ulteriormente identificados con instrumentos técnicos o recetarios de la acción pastoral'5 Pese a lo anterior, una contribución importante que ambos dieron a la

4 Cf. M. Midali, Teologia pastorale o pratica. Cammino storico di uma reflexione fondante e scientifica. (Roma 1985) 17-85; A. Vigueras, "Que cabe à Igreja fazer hoje? A concepção de teologia prática em Karl Rahner» en Perspectiva Teológica 36 (2004) 99-124; C. Schneider-Harpprecht, «Aspectos históricos e concepções contemporâneas da teologia prática» en C. Schneider-Harpprecht (org.), Teologia prática no contexto da América Latina (São Leopoldo 1998) 36-62.

5 Según Floristán, el proyecto de Stepan Rautenstrauch se caracteriza por su aspecto pragmático y por la dimensión de recetario práctico o canónico para la pastoral del clero. Cf. C. Floristán, Teología práctica: teología y praxis de la acción pastoral (Salamanca 1991) 110. Para Hock, Scheleirmacher concibió la teología práctica como disciplina que ofrecía el instrumental técnico por el cual la jerarquía de la Iglesia dirigía y reglamentaba las diferentes funciones y las manifestaciones de la vida eclesiástica, tales como el culto, la catequesis, el acompañamiento y la propia forma da vivencia comunitaria de la fe. Cf. L. C. HocH, «O lugar da teologia prática como 
teología práctica/pastoral fue que esta se comprendiera como un «saber empíricamente supervisable e históricamente comprobable», recurriendo a los «conocimientos básicos de los métodos de investigación de otras ciencias» ${ }^{6}$.

Estos dos elementos de sistematización de la teología pastoral/práctica por parte del mundo germánico fueron retomados y prolongados en los siglos XIX y XX. Del lado católico, eso se dio primeramente a través de nuevos esfuerzos de fundamentación, ya sea a partir de una orientación bíblico-teológica con J.M. Sailer (1751-1832), A.S. di Fulda y P.C. di Treviri, sea por la impostación eclesiológica con A. Graf (1814-1867), o por el camino de la teología pastoral con J. Amberger (1816-1889) y otros. En esta última perspectiva, la sistematización fue definida como «cura de almas» y fundada en el triple oficio de Cristo: sacerdote, profeta y rey, y teniendo como disciplinas la catequética, la homilética, la liturgia y la odegética. Más allá de referencias a las fuentes de la teología-Biblia, tradición, dogma- la teología práctica recurría en el momento de la aplicación a las ciencias que estudiaban la condición humana en sus distintos aspectos: psicología, pedagogía, medicina, psiquiatría y sociología, esta última entendida como exposición de las relaciones dominantes en la vida sociocultural ${ }^{7}$. Pensados como teología de los pastores que cuidan las almas, los manuales de esta tendencia se dejaron subordinar por la norma canónica, aproximándose también a los manuales de moral. No obstante, a partir de 1920, la teología pastoral así definida entró en crisis. Varios esfuerzos de reelaboración surgieron entonces, bajo el influjo del movimiento litúrgico y catequético, por un lado, y de la teología querigmática por el otro. Pero, las dificultades impuestas por la

disciplina teológica» en C. Schneider-Harpprecht (org.). «Aspectos históricos e concepções contemporâneas da teologia prática», 25.

6 Según Vigueras, esta es la lectura que Josep Müller hace del aporte de Rautenstrauch a la cientificidad de la teología pastoral, que tiene que ver con el método científico y nuevas formas didácticas. Cf. A. Vigueras, "Que cabe à Igreja fazer hoje? A concepção de teologia prática em Karl Rahner», 102. Para Schneider-Harpprecht, Schleiermacher defendía el uso, de parte de la teología práctica, de los métodos de pesquisa de otras ciencias, como la filosofía, la ética, la historia, la música, la teoría del estado y de otras áreas, en cuanto ciencias auxiliares. Cf. C. SchneiderHarpprecht, «Aspectos históricos e concepçôes contemporâneas da teologia prática», 38.

7 Cf. M. Midali, Teologia pastorale o pratica. Cammino storico di uma reflexione fondante e scientifica, 38-44. 
crisis modernista y la neoescolástica reinante hacían la tarea más difícil. Pese a lo anterior, F. X. Arnold emprendió un proyecto de renovación de la teología pastoral, retomando la cuestión de su cientificidad y situando su dimensión teologal en el ámbito de la revelación. Ella no podía, según él, ser reducida a una mera técnica o aplicación de los resultados de otras disciplinas teológicas a la cura de las almas. Su objetivo era la acción de la Iglesia y esta se realizaba en la predicación, en los sacramentos y en la cura de las almas. No solo los pastores eran su sujeto, sino también el conjunto de todos los bautizados ${ }^{8}$.

En los países de lengua francesa, las tensiones que desde el siglo XVIII opusieran Iglesia y Estado, llevaron a la exclusión de la teología de las universidades públicas. Esto sucedió también en los países de tradición latina, incluso en los de América Latina. Las ciencias humanas nacientes en el siglo XIX, sobre todo la sociología, la etnología, la psicología y el psicoanálisis, se interesaron por la religión y por el cristianismo, aunque muchas veces se hayan presentado como substitutos a las lecturas hechas por la teología ${ }^{9}$. Esto, por su vez, no produjo en este periodo ninguna reflexión sobre la pastoral como lo hizo la teología alemana. Después de la Primera Guerra Mundial creció la conciencia de ruptura entre la Iglesia y el mundo moderno. Lo que se dio a partir de la Acción Católica y sobre todo por la JOC, el movimiento de los curas obreros, y por varios estudios importantes de la sociología religiosa ${ }^{10}$. En este periodo, la teología francesa experimentó también una gran vitalidad a través de las escuelas de Saulchoir y de Fourvière, y de la así llamada Nouvelle Théologie ${ }^{11}$. Se habla entonces de pastoral de conjunto y de evangelización de los distintos ambientes -familia, barrio, mundo, trabajo, medios de comunicación, etc.- que es asumida por la Acción Católica especializada, en la que laicos desempeñaron un papel muy importante. Se elaboró el método ver-juzgar-actuar, que al momento de ver, asume los resultados de las investigaciones de las ciencias humanas, en especial de

8 M. Midali, Teologia pastorale o pratica. Cammino storico di uma reflexione fondante e scientifica, 61-74.

9 Cf. J. Joncheray, «Théologie et sciences humaines» en G. Routhier - M. Viau, Précis de théologie pratique (Bruxelles-Montreal 2004) 167-178.

10 Dentro de esos estudios, destaca: G. LE Bras, «Pour um examen détaillé et pour une explication historique de l'état du Catholicisme dans les diverses regions de la France», RHEF 17 (1931) 425-449.

11 Cf. R. Gibellini, Panorama da teologia no século XX (São Paulo 2002). 
la sociología, teniendo como rasgo propio el proceso de discusión con los distintos agentes de evangelización ${ }^{12}$.

El Concilio Vaticano II fue de gran importancia para la teología práctica/pastoral católica, ya que se auto-comprendió como un concilio pastoral, habiendo conferido a la fe y a la teología cristiana un carácter eminentemente pastoral. Esto es lo que muestran sus Constituciones: Dei Verbum, que ofrece una visión histórico-salvífica y existencial de la Revelación; Lumen Gentium, que comprende a la Iglesia como misterio de comunión y servicio; Sacrosantum Concilium, que muestra el papel de la liturgia y de la eucaristía en la vida de la Iglesia; Gaudium et Spes, explícitamente denominada Constitución Pastoral y que se ocupa de la relación de la Iglesia con el mundo contemporáneo; sus Declaraciones y Decretos: algunos preocupados en dialogar con otras iglesias cristianas: Unitatis Redintegratio, Orientalium Ecclesiarum, con otras religiones: Nostra Aetate, con el mundo de la comunicación: Inter Mirifica; otros en ofrecer orientaciones a los distintos seguimientos de la Iglesia: laicos: Apostolica Actuositatem, presbíteros: Prebyterorum Ordinis, eligiosos/as: Perfectae Caritatis, obispos: Christus Dominus; o en indicar propuestas para la formación de seminaristas: Optatam Totius, la educación cristiana: Gravissimun Educationis, y asegurar la libertad religiosa: Dignitatis Humanae.

El Concilio hace de la Iglesia, pueblo de Dios, el sujeto de la acción pastoral. Esto quiere decir que no son solo los pastores -obispos y presbíteros- los responsables de la pastoral, sino todos los bautizados. Esta acción es captada de forma histórica, o sea, la Iglesia debe estar atenta a los «signos de los tiempos», a las condiciones y posibilidades que cada época y lugar histórico imponen y ofrecen a la acción pastoral ${ }^{13}$. Esta acción tiene dimensiones intra-eclesiales (liturgia, catequesis, sacramentos, dirección espiritual, coordinación de comunidades e Iglesias) y extra-eclesiales (educación, acción caritativa, comunicación social, etc.). Los grupos a los cuales esta acción se dirige son variados: niños, jóvenes,

12 Cf. M. Midali, Teologia pastorale o pratica. Cammino storico di uma reflexione fondante e scientifica, 74-83.

13 Según el texto conciliar, «es deber de todo el Pueblo de Dios y, sobre todo, de los pastores y teólogos, con la ayuda del Espíritu Santo, saber oír, discernir e interpretar los diversos lenguajes de nuestro tiempo, y juzgarlos a la luz de la Palabra de Dios, de modo que la verdad revelada pueda ser cada vez más íntimamente percibida, mejor comprendida y presentada de un modo conveniente» $(G S, 44 \mathrm{~b})$. 
familias, migrantes, turistas, pobres, enfermos, estudiantes, obreros, artistas, científicos, etc. La Iglesia establece un diálogo de colaboración y solidaridad con varios miembros del pueblo de Dios, con personas de otras Iglesias cristianas y de otras religiones, además de los hombres y mujeres de buena voluntad.

Los textos conciliares tienen conciencia del papel de las investigaciones y descubrimientos recientes de las ciencias, de la historia y de la filosofía en la cultura contemporánea. Incentivan, por ello, a la teología a no ignorarlos, sino a «buscar constantemente, de acuerdo con los métodos y exigencias propias del conocimiento teológico, la forma más adecuada de comunicar la doctrina a los hombres de su tiempo» ${ }^{14}$. Es importante para esto conocer «no solo los principios teológicos, sino también los datos de las ciencias profanas, principalmente la psicología y la sociología, para que así los fieles sean conducidos a una vida de fe más pura y adulta $»^{15}$. Además de estos saberes, la literatura y las artes también deben ser de interés para la teología, pues «dan expresión a la naturaleza del ser humano, a sus problemas y a la experiencia de sus intentos por conocerse y perfeccionarse a sí mismos y al mundo». Identifican «su situación en la historia y en el universo", dan "a conocer sus miserias y alegrías, necesidades y energías», y desvelan «un futuro mejor» ${ }^{16}$. Los que se dedican a la teología deben «colaborar con los especialistas de otras áreas del saber, poniendo en común trabajos y conocimientos» ${ }^{17}$.

Además de esta perspectiva de fondo de los textos conciliares, el documento dedicado a la formación de los presbíteros -Optatam Totius- subraya el carácter pastoral de las disciplinas teológicas (Sagrada Escritura, teología dogmática, teología moral, derecho, liturgia) y la importancia de estudiarlas en esta perspectiva. Propone incluso la enseñanza de disciplinas explícitamente pastorales (catequética, homilética, liturgia, dirección espiritual, formación para la pastoral social), además del co-

14 Cf. Concilio Vaticano II, Gaudium et Spes, 62b.

15 Concilio Vaticano II, Gaudium et Spes, 62b.

16 Concilio Vaticano II, Gaudium et Spes, 62c.

17 Concilio Vaticano II, Gaudium et Spes, 62g. Además de la psicología, de la sociología, del arte y de la literatura, Gaudium et Spes, 52 habla de la necesidad de conocimientos en biología y medicina, Ad Gentes habla de la importancia de la etnología, de la lingüística, de la historia de las religiones y de la ciencia comparada de las religiones, e Inter Mirifica evoca el interés por los estudios de comunicación. 
nocimiento de otras ciencias importantes para la pastoral, especialmente la pedagogía, la psicología y la sociología ${ }^{18}$.

Veamos ahora cómo la teología práctica/pastoral se desarrolló en el medio protestante alemán después de Schleiermacher. La influencia de Hegel fue importante en los manuales de P. Marheinke (1780-1846), C. I. Nitzsch (1787-1868) y C. Palmer (1811-1875), preocupados de la cientificidad de la teología práctica, buscando darle una perspectiva sistemática, en la cual la Iglesia apareciera como sujeto de la acción práctico/pastoral ${ }^{19}$.

De 1850 a 1950 se destacan las siguientes tendencias: 1) la de marca empírica, presente en los manuales de T. Harnaz (1817-1889), G. Zezschwitz (1825-1886), C. Archelis (1838-1892), A. Krauss (1836-1892), que se distancian de la perspectiva anterior y asumen la influencia del historicismo, que pasa a dominar los estudios de varias acciones eclesiales: predicación, catequesis, cura de almas, coordinación de la comunidad. En estos estudios adquieren importancia la psicología experimental y la sociología. A pesar de afirmarse la relación entre teología e Iglesia, el énfasis mayor era dado al individuo. El acento analítico lleva, no obstante, a la pérdida de la dimensión orgánica y unitaria de la reflexión de los manuales anteriores; 2) la de la teología de la Palabra, bajo la influencia de K. Barth (1886-1968), que hizo que el énfasis fuera dado a la fe (como evento) y a la Palabra (como adviento), y no tanto al dato empírico. La teología científica se tornó entonces secundaria en relación a la experiencia de la fe. La teología se entiende como teología de la predicación/querigmática. En ella la homilética adquiere una gran relevancia; 3) la tendencia a retomar la reflexión sobre la relación entre Iglesia y mundo. Tres propuestas se destacan aquí: $1^{\circ}$ ) la de A. D. Müller, que bajo la influencia de la teología de la cultura de Tillich propone una teología práctica que lleve en cuenta la secularización. Para ello, él busca pensarla como una doctrina teológica que se pone al servicio del Reino de Dios en la Iglesia y, a través de ella, en el mundo. 20) la tendencia de E. Hertzsh, que reanuda el diálogo con las ciencias humanas, tomadas como disciplinas auxiliares. Para él, la homilética supone la retórica y la estilística; la catequética esta vinculada a la pedagogía y a la didáctica; la liturgia necesita del arte y de la música; la «cura de almas» requiere la

\footnotetext{
18 Cf. Concilio Vaticano II, Optatam Totius, 20.

19 Concilio Vaticano II, Optatam Totius, 29-32.
} 
psicología; el liderazgo comunitario tiene que ver con el derecho; $3^{\circ}$ ) la de O. Haendler, que une la penetración teológica con la competencia psicológica de lo profundo (de origen rusa) ${ }^{20}$.

En el ambiente protestante norteamericano de la década de los 30 del siglo XX, bajo la influencia del pragmatismo empírico y del «evangelio social», surgió un movimiento pastoral conocido como Clinical Pastoral Training o Clinical Pastoral Education. Sus precursores fueron el teólogo Antonio Boisen y el médico Richard Cabot. A partir del arte, la escucha y de la presentación de casos, se buscaba ayudar a los pacientes/ enfermos a encontrar el camino de la cura. Los estudios de Carls Rogers hicieron que su connotación clínica se ampliara al campo pastoral -Pastoral Counseling- ganando así mayor incidencia y eficacia en el seno del ministerio de los pastores y agentes pastorales. S. Hiltner, psicólogo y teólogo presbiterano, le dio sistematicidad a lo anterior. Introdujo en la praxis pastoral la técnica del diálogo a partir del análisis atento a ejemplos concretos. A partir del método rogeriano, él propuso como perspectiva general: la atención pastoral (sheperding), los procesos de comunicación (communicating) y los dinamismos organizativos (organizing). La atención pastoral es leída a la luz del amor a Dios y al prójimo. Sus contenidos concretos son: intervención terapéutica (healding), en función de la cura y salvación; acción de sustentación (sustaining), realizada según métodos adecuados; actividad de guía (guiding), de tipo educativo, moral y espiritual. El conjunto de esta primera perspectiva corresponde a la pastoral theology. Los procesos de comunicación tienen que ver con la transmisión del evangelio. Varios elementos de la catequética, de la homilética, de la misionología, de la publicidad eclesial, vistos bajo la perspectiva del testimonio, son retomados, dando origen a la educational and evangelistic theology. Los dinamismos organizativos indican la acción del discipulado, entendido como servicio a la formación de la comunidad de los más débiles, según los criterios del evangelio. Toda la vida eclesial es estudiada en esta perspectiva. Son recuperados, así, los elementos de la conducción de la comunidad, de la sociología pastoral, del derecho y de la pastoral litúrgica, dando origen a la eclesiastical theo$\log y$. Hiltner distingue todavía las disciplinas teológicas operativas de las disciplinas lógicas. Las primeras se interesan por la acción y reflexionan

20 Cf. M. Midali, Teologia pastorale o pratica. Cammino storico di uma reflexione fondante e scientifica, 44-52. 
sobre la vida cristiana actual. Para eso necesitan recurrir a las ciencias profanas correspondientes: psicología y sociología. Las demás -teología bíblica, histórica, sistemática, moral, estética- estudian el desarrollo y el significado de la fe contenida en los textos escritos, en el pueblo, en los eventos y en la experiencia que dieron origen a dichos textos. Asimismo, deben recurrir a las disciplinas profanas correspondientes: lingüística, arqueología, paleografía, historia ${ }^{21}$.

Este breve sobrevuelo a la historia de la teología práctica/pastoral muestra algunas constantes en su relación con los otros saberes y la función que estos tienen en el interior de ella. La preocupación con la cientificidad de este tipo de teología lleva a dos tipos de actitud epistemológica: o se enfatiza la dimensión teologal, escogiendo para ello referencias filosófico-sistemáticas de peso y ejes teológicos que aseguran tal dimensión; o se privilegian las exigencias del hacer científico, lo que parece salvar mejor la cientificidad de algunos resultados obtenidos, pero con el costo de una pérdida de sistematicidad en la dimensión teologal. La primera actitud es del orden de una teología fundamental práctica/pastoral y la segunda del orden de una teología práctica/pastoral aplicada. No siempre es posible asegurar ambas en el mismo proyecto, lo que sin duda es problemático. En casi todos todavía se da un lugar importante a los otros saberes, filosófico en la primera actitud, y de las ciencias humanas en la segunda. No queda claro cuál es el estatuto de estos saberes en el quehacer teológico: ¿El de ciencia auxiliar? ¿El de suplencia a la carencia de ciertos recursos en el quehacer teológico? ¿El de substituto del saber teológico? ¿El de interlocutor real? Veamos de qué forma esto aparece en los actuales proyectos de teología práctica/pastoral.

\section{LOS OTROS SABERES EN LOS ACTUALES MODELOS DE TEOLOGÍA PRÁCTICA/ PASTORAL}

Antes de trazar un panorama de los principales modelos de teología práctica/pastoral en la actualidad y su relación con los otros saberes en la lectura teológica de la realidad, es importante destacar dos tendencias que adquirieron importancia a partir de los años 60 del siglo XX. La primera fue el crecimiento de la influencia de las ciencias humanas en la lectura e interpretación del ser humano. La sociología, la política, la

21 M. Midali, Teologia pastorale o pratica. Cammino storico di uma reflexione fondante e scientifica, 52-61. 
economía, entre otras, se transformarán en teorías totales de la realidad, y el psicoanálisis se tornó teoría englobante de la cultura, además de su importancia terapéutica. Esta relevancia sociocultural hizo que estas ciencias ejercieran un gran atractivo sobre la teología. Otra tendencia, relacionada con la anterior, fue la creciente importancia de las ciencias de la religión, que estudian el fenómeno religioso de forma no confesional, planteando por ello, una mayor neutralidad en la investigación, además de una mayor cientificidad y colocándose, entonces, como alternativas al saber teológico, que por ser confesional pasa a ser considerado como menos científico ${ }^{22}$.

Son varios los intentos de trazar una tipología de los principales modelos de teología práctica/pastoral vigentes en la actualidad ${ }^{23}$. Optamos por el de J. Audinet, por su carácter sintético y abarcador, enriqueciéndolo con datos de otros autores. Audinet inicia su estudio sobre la diversidad de las teologías prácticas de hoy recordando el Primer Congreso Internacional de Teología Práctica, ocurrido en Ottawa el año 1988. Al mismo tiempo en que había cierta unidad al respecto del vocabulario, afirma él, tal unidad desaparecía cuando se explicitaba el significado de los términos, sobre todo del de práctica ${ }^{24}$. Audinet ilustra esto presentando los itinerarios de Don Browning, de Chicago, y Norbert Greinacher, de Tübingen. En seguida propone una tipología con tres modelos: el de las teologias prácticas empíricas, el de las teologías prácticas críticas y el de las teologías prácticas fundamentales. Veamos cuál es la orientación fundamental de cada una, la relación que establecen con otros saberes, y el estatuto que estos poseen en el quehacer teológico.

22 Véase a ese sujeto: P. GISEL, La théologie face aux sciences religieuses: différences et intéractions. (Genève 1999); G. De Mori - E. Cruz. (Org.). Teologia e Ciências da Religião. A caminho da maioridade acadêmica no Brasil (São Paulo 2011); J. AudiNET, «Théologie et sciences religieuses» en J. Audinet, Écrits de théologie pratique (Ottawa 1995) 258-277.

23 Véanse las propuestas de M. Midali, Teologia pastorale o pratica. Cammino storico di uma reflexione fondante e scientifica, 151-337; C. SCHNEIDER-HARpprecht, "Aspectos históricos e concepções contemporâneas da teologia prática», 36-62; J. Audinet, «Diversité de théologies pratiques» en J. Audinet, Écrits de théologie pratique (Ottawa 1995) 239-258.

24 Ver el significado de práctica y praxis propuestos en el Primer Coloquio de Teología Práctica de la Facultad de Teología de la Universidad Católica de Chile, en el 2010, por A. Parra - F. de Aquino Júnior - G. De Mori, Teología y Vida, LI (2010) 445 ss. 
Teologías prácticas empíricas

El término empírico proviene, según Audinet, de la revista Journal of Empirical Theology, de origen holandés. Desde su perspectiva anglosajona percibe la práctica como algo "derivado o guiado por la experiencia». Esto quiere decir «experimentación» y «adquisición personal». J.A. van der Ven presenta los diversos países donde este modelo es importante y el sentido que empírico tiene en este modelo ${ }^{25}$. En Holanda, cuenta él, la primera cátedra de teología pastoral fue creada en 1964, en la facultad de teología de Nimega; juntamente con otras dos creadas en la facultad de ciencias sociales: la de sociología y la de psicología religiosa. Se buscaba un trabajo multidisciplinar de educación y de teología pastoral, en el cual se juntaran investigadores del área pedagógica. En Estados Unidos, fue a partir de la psicología clínica y de la orientación de la Escuela de Chicago que esta tendencia se consolidó. En Alemania, algunos autores privilegiaron la psicología clínica y la psicología social, y otros las ciencias sociales en general, agregando el término crítica al término empírica.

En la facultad de Nimega, los fundamentos de la teología empírica se encuentran en el Handbuch der Pastoraltheologie, editado por Rahner. El método utilizado era el de la multidisciplinariedad. En la primera etapa, el teólogo trabajaba como investigador en ciencias sociales para recoger informaciones pertinentes, fiables y empíricamente válidas en un cierto dominio. En la segunda etapa, él hacía una reflexión sobre los resultados de la investigación empírica desde el punto de vista teológico. Lo teológico era variable, podía ser el clásico tema de la jerarquía de las verdades o el tema de la teología como historia/servicio de la salvación, etc.

Los investigadores involucrados en ese proyecto quedaron insatisfechos con este método de las dos etapas y pasaron al método interdisciplinar, que consistía en asumir conceptos, métodos y técnicas de otra ciencia integrándolos a la propia. Según J. A. van der Ven, este método es utilizado en muchos campos del saber, también en la exégesis y en la teología ${ }^{26}$. Su uso debe llevar en consideración los siguientes principios

25 J. A. VAN DER VEN, «L'avenir de la théologie pratique», Laval théologique et philosophique, 47 (1991) 231-240.

26 Según Van der Ven, en la teología, la ética de Santo Tomás es inconcebible sin la de Aristóteles, la escuela de Tübingen impensable sin el idealismo, la teología sistemática de Tillich no existiría sin la psicología del profundo y la filosofía existencial, 
hermenéuticos: 1) el investigador empírico participa del mundo de los que son objeto de su investigación, 2) él debe considerar el contexto en que viven, 3) debe estudiar la historia de ese mundo y de ese contexto; 4) los pensamientos, emociones y prácticas de los que son investigados deben estudiarse desde una perspectiva ideológico-crítica. Además de estos principios el método sigue las siguientes etapas: $1^{\circ}$ ) elaboración del problema teológico; $2^{\circ}$ ) inducción teológica, que consiste en ver qué tipo de personas, representaciones, acciones, procedimientos y estructuras pudieran interesar en la investigación; $3^{\circ}$ ) deducción teológica, que demanda la elaboración de un procedimiento conceptual de la investigación, el cual, a su vez, se traduce en una hipótesis e instrumento de investigación; 40) test empírico-teológico, que supone la aplicación de la investigación y la sistematización de los resultados obtenidos; 50) evaluación teológica, que prueba o falsea las hipótesis de la investigación.

\section{Teologías práticas críticas}

Ese modelo es el de las teologías que se entienden como crítica de las instituciones ${ }^{27}$. El término crítico es entendido como discernimiento, evaluación y análisis, y el término institución como el conjunto de las formas por las cuales se manifiesta un grupo. En el caso de la teología, el grupo en cuestión es el cristianismo y sus prácticas. Estas son el resultado de una tradición de fe, constituida de experiencias, lenguajes y aptitudes, que a la vez, solo son aprehensibles en las instituciones en las cuales ellas se dan y que a la vez las engendran también. Tales instituciones son captadas como organizaciones y sistemas de pensamiento, ritos y discursos. Por lo tanto, la preocupación de la teología práctica que surge de esta perspectiva no es con las prácticas empíricas de la pastoral, sino con sus presuposiciones, con lo que está por detrás de los comportamientos actuales. No se trata mucho de lo «¿qué hacer?», sino de "¡cómo funcionan las cosas?». El elemento teológico es dado de antemano, pues es en el nombre de la encarnación que tal proyecto se realiza. El recurso a los saberes de otras ciencias como la historia, la psicología y la sociología es importante, pero no se trata, por ejemplo, de estudiar las distorsiones

la teología de Metz incomprensible sin la escuela de Frankfurt, la exegesis de los últimos siglos impensable sin la historiografía crítica, la hermenéutica moderna, el estructuralismo, la crítica literaria. Cf. J. VAN DER VEN, «L'approche empirique en théologie», Laval théologique et philosophique 2 (1994) 114-115.

27 Cf. J. Audinet, «Diversité de théologies pratiques», 250-254. 
de lo que ocurre en la Iglesia solamente en la perspectiva de la sociología de las instituciones, sino de interrogarse sobre el hecho de que siendo una institución análoga a las demás, sea también lugar de salvación. Por lo tanto, tratase de pensar la relación de salvación con las formas de funcionamiento de un grupo.

La novedad de ese tipo de modelo es que no parte de la cosmología o de la ontología, sino de la sociedad y de la acción. Trátase, según David Tracy, «de la correlación recíproca y crítica entre la teoría y la praxis interpretadas del hecho cristiano, con la teoría y la praxis interpretadas de la situación contemporánea ${ }^{28}$. Para realizar eso es necesario elaborar una serie de categorías que permitan captar la tradición cristiana y, al mismo tiempo, la situación contemporánea, mostrando la relación de una con la otra y lo que caracteriza la singularidad cristiana. De entre las categorías privilegiadas, hay que destacar al análisis del lenguaje, al análisis institucional, a la comunicación, a la praxis, entre otras. Según Audinet, ese tipo de teología práctica dio nueva fecundidad y vitalidad a la pastoral, como lo muestran las teologías del mundo, las teologías de la liberación, la teología de la secularización, de la negritud, de género, de ecología, etc. En todas ellas se percibe que el lugar de la reflexión se desplaza. La crítica de la sociedad se torna una reflexión sobre la Iglesia que se instituye en la sociedad. Los principios que permiten ese desplazamiento son varios, según los distintos teólogos: la reserva escatológica, la causa de Jesús, el principio de esperanza, la liberación del género humano en todas sus dimensiones, el cuidado de la creación, etc.

Este tipo de teología mostró que solo podía cumplir su tarea como inteligencia de la relación de la Iglesia con la sociedad. La teología de la liberación latinoamericana realizó eso de manera emblemática, como lo muestra Juan Luis Segundo, uno de sus principales representantes, y el teólogo español Casiano Floristán, que escribió un tratado de teología pastoral a la luz de los conceptos fundamentales de la Teología de la Liberación $^{29}$.

28 Cf. D. Browning, «Methods and Fondations for Pastoral Studies in the University» en A. Visscher, (dir.). Les études pastorales à l'université/Pastoral Studies in the University Setting (Ottawa 1990) 65. Citado por J. Audinet, "Diversité de théologies pratiques», 252.

29 Cf. C. Floristán, Teología práctica: teoría y praxis de la acción pastoral (Salamanca 1993). Para el análisis aquí propuesto, cf. C. Schneider-Harpprecht, «Aspectos históricos e concepções contemporâneas da teologia prática», 53-57. 
La obra La liberación de la teología ${ }^{30}$ es una de las primeras en las cuales el teólogo uruguayo reflexiona sobre la teología como práctica. El contexto en el cual él escribió esta obra era el de América Latina de los años 1970, marcado por una gran efervescencia política e ideológica. En esa obra él muestra cómo la Teología de la Liberación invierte la tradicional subordinación de la práctica a la teoría, en que la práctica funcionaba como aplicación de la Palabra de Dios a las realidades humanas en el interior de un laboratorio inmune a las tendencias y luchas ideológicas. El propio quehacer teológico, dice él, consiste en actos de interpretación que relacionan la comprensión de la Palabra de Dios dirigida a nosotros, aquí y ahora, con la comprensión de la realidad presente. ¿Qué es lo que hace un teólogo de la liberación? Lo que debe hacer es procurar una cooperación entre sí de todas las disciplinas de la teología y de estas con las ciencias sociales, especialmente con la sociología, y con la crítica de las ideologías. Para Segundo, el teólogo «se ve obligado a cada paso a colocar juntas las disciplinas que le abren al pasado y las que le explican el presente» ${ }^{31}$. El círculo hermenéutico, así creado, no le permite ser simple observador de la realidad, pues le muestra que la comunicación humana es mediada por la política. El acto de interpretar ya es confirmar o poner en cuestión el statu quo. La cooperación con las ciencias sociales es necesaria para interpretar la realidad. Ellas no dirigen, sin embargo, la acción pastoral de la Iglesia, sino que funcionan como compañeras de la teología, proporcionándole un instrumento de análisis ideológico que detecta la infiltración de las ideologías económicas y políticas en la fe de la Iglesia.

El manual de Casiano Floristán fue elaborado teniendo en cuenta el contexto de América Latina, la práctica eclesial de las comunidades de base (CEBs) y la teología de la liberación. La reflexión sobre la Iglesia que él propone toma en cuenta la renovación conciliar que había tornado posible una visión eclesiológica comprometida con los pobres y marginados, y una lectura de la teología en diálogo con las ciencias humanas. La acción de la Iglesia tiene como referencia la acción de Jesús de Nazaret. El autor divide su obra en dos partes: 1) teología práctica general y 2) teología práctica especial. En la primera, él aborda las raíces bíblicas, la historia, la teoría de la teología práctica como teología de la

\footnotetext{
30 J. L. Segundo, La liberación de la teología (Buenos Aires 1975).

31 J. L. Segundo, La liberación de la teología, 10.
} 
acción pastoral y la cuestión de los agentes pastorales. En la segunda parte, él estudia la acción de la Iglesia en base a cinco ángulos: 1) el kerigma (misión), 2) la didascalia (catequesis), 3) la liturgia (liturgia/homilética), 4) la koinonía (comunidad) y 5) la diakonía (servicio).

La descripción de la práctica de Jesús y de la Iglesia primitiva plantea los criterios pastorales para la acción eclesial. Según Floristán, el Reino de Dios es el centro de la praxis de Jesús. Se trata de algo que ya está presente, pero también es esperado como algo escatológico. Sus protagonistas son los pobres, los que sufren y necesitan de justicia. Sus principios básicos son: en el nivel económico: el compartir los bienes materiales con los pobres; en el nivel político: la esperanza de justicia y de igualdad que culmina en la crítica a los poderosos; en el nivel éticosocial: la transformación de los valores, posibilitada por una visión de fe que defiende la dignidad del ser humano, la solidaridad y un amor universal que supere los conflictos. La experiencia de pascua convirtió a los discípulos en testigos y misioneros del evangelio de la vida, muerte y resurrección de Jesucristo.

Para Floristán la teología de la liberación es una teología práctica fundamental. Su presupuesto es que toda teología que no surge de la práctica es irrelevante y toda teología que sirve para transformar la realidad es teología práctica. La práctica, dice él, es interacción social y compromiso militante, transformación de estructuras y actitud crítica, renovación del sistema social y emancipación social. El cristianismo es ortopraxis. La teología práctica es teoría de la praxis de los cristianos que reconocen la realización de la fe en la historia y en la sociedad.

\section{Teologías prácticas fundamentales}

Ese modelo de teología práctica interroga no sobre las formas empíricas de la práctica o sobre los funcionamientos que las instituyen, sino más bien sobre la razón de ser de una práctica cristiana ${ }^{32}$. ¿Qué significa el cristianismo como práctica? No hay duda que las sociedades contemporáneas se piensan en términos de acción, que los seres humanos hoy día se identifican como actores y agentes. Pero, ¿y el cristianismo? No solo en sus formas recibidas, reconocidas e instituidas a través de la historia, sino en el acto que lo engendra y lo hace existir en cuanto tal en el seno

32 Cf. J. Audinet, «Diversité de théologies pratiques», 254-258. 
de las sociedades, ¿cómo asume esa forma de entenderse de la cultura actual? ¿Qué es lo que funda el ser común de los seres humanos cristianos?

Tales cuestiones no son específicas de la teología práctica, sino el medio por el cual ella se encuentra con la teología fundamental. El itinerario de las teologías prácticas permite, por eso, abordar tales cuestiones de manera original. Hay que pensar una teología ligada a la práctica en el concierto de los demás saberes y situar su aporte a la cultura. Para eso, es necesaria una reflexión sobre las relaciones entre el discurso científico y el teológico. Según Audinet, ese tipo de reflexión ha sido hecho en países en donde la teología no fue excluida del mundo universitario. Eso se dio, sobre todo, en facultades de pastoral y de praxeología, que más fácilmente dialogan con las ciencias sociales y se entienden como ciencias de la acción religiosa. En algunos casos, más que centrarse en la acción de las iglesias cristianas, esas facultades tienen ampliado el espacio de la reflexión volviéndose a la acción religiosa en general. Ese tipo de abordaje tiene como ambición, más allá de la investigación sobre la acción, dar cuenta de la operación pastoral según categorías de las ciencias de la acción. Para eso, recurren a los procedimientos de la operación científica: hipótesis, experimentación, verificación, y los articulan con una axiología, en búsqueda de asegurar para cada momento la especificidad de la acción religiosa.

Audinet se pregunta sobre el porqué de ese nuevo tipo de teología práctica. Según el, citando a Émile Poulat, «trátase de vincular la práctica o su ausencia al que es su justificación última, a saber, la fe, de la cual ella es una de las expresiones o, al revés, la no aceptación, la negación ${ }^{33}$. Con eso, continúa Audinet, está abierta la posibilidad de una antropología de la fe. Esa, por su vez, invita a una mirada sobre el dado cristiano desde el punto de vista de aquel que lo recibe: el ser humano en lo que lo constituye en su humanidad. ¿Qué representa la fe cristiana? En el sentido cristiano, el acto de fe es un acto particular de pertenencia en una sociedad, es el acto fundador de una identidad específica en una cultura, es el acto iniciador de ciertas escuelas de acción, pues, en ella misma, predomina la intención de universalidad, para allá de toda pertenencia, y de fraternidad, para allá de toda identidad. Audinet ve en eso el fundamento de una antropología del cristianismo que permite ir al encuentro

33 J. Audinet, «Diversité de théologies pratiques», 257. 
de la tradición teológica en toda su fuerza y ofrece una mirada sobre el ser humano en la sociedad actual.

Un ejemplo de teología práctica fundamental es el de Don Browning, teólogo norteamericano que propone una reflexión sobre la teología práctica en el contexto de las ciencias de la cultura, abriendo un diálogo crítico con las ciencias sociales y la filosofía práctica ${ }^{34}$. Según él, las comunidades religiosas son la base de la reflexión teológica. Ellas desarrollan historias determinadas por las prácticas religiosas en las cuales, a través de actos de interpretación, correlacionan la situación presente con las tradiciones normativas de su actuar. Surgen nuevos desafíos, sus prácticas pueden entrar en crisis. Eso las obliga a reflexionar sobre las implicancias teóricas de la práctica actual y a establecer un diálogo con las cuestiones actuales y los textos de su tradición, en búsqueda de un nuevo horizonte en el cual se encuentren criterios teológicos para desarrollar una práctica adecuada. En diálogo con las filosofías del actuar, que cuestionan el predominio de la razón teórica y técnica y retoman la phronesis aristotélica, Browning dice que todas las comunidades se orientan por la sabiduría práctica. A la luz de la hermenéutica de Gadamer, él sustenta que en cada acto de interpretación la práctica de los intérpretes está presente y codetermina la interpretación. Si comprensión, interpretación y aplicación están íntimamente relacionadas, entonces todas las ciencias humanas tienen que ser reconocidas como internamente prácticas e históricas. Toda la teología se torna, por eso, teología práctica fundamental, o sea, reflexión crítica sobre el diálogo de la Iglesia con las fuentes cristianas y otras comunidades de experiencia e interpretación con miras a dirigir su acción por la vía de la transformación individual y social.

La teología fundamental de Browning posee cuatro elementos: el descriptivo, el histórico, el sistemático y el estratégico. En el momento descriptivo, son analizadas las prácticas contemporáneas con las teorías a partir de las cuales nacen las preguntas para la reflexión teológica. En el momento histórico, el teólogo se pregunta por los textos que hacen parte de su historia efectiva, por lo que influyen realmente en su práctica. En el momento sistemático, examina los temas generales del evangelio que responden a las preguntas generales que caracterizan las situaciones

34 Ver a este propósito: C. SCHneider-Harpprecht, «Aspectos históricos e concepções contemporâneas da teologia prática», 36-62. 
presentes. En el momento estratégico, se pregunta sobre cómo entender la situación en que tiene que actuar, cuál debería ser su práctica, cómo defender normas determinadas de su práctica y qué estrategias usar. En ese momento se preocupa con las prácticas internas y externas de la Iglesia, asumiendo su influencia social.

Contra el relativismo del pragmatismo posmoderno, que niega la existencia de valores universales, Browning defiende la idea de Habermas, según la cual el actuar en las sociedades modernas requiere la mediación entre intereses conflictivos y discursos. Estos solo no son distorsionados por ideologías si todos los participantes se someten a la crítica de las ideologías y se dejan dirigir por valores básicos como la comprensión, la verdad, la sinceridad y la legalidad. En su teología práctica fundamental él menciona cinco dimensiones centrales para la reflexión teológica: 1) la visionaria, que tiene que ver con las narrativas y las metáforas que forman la autocomprensión de las comunidades; 2) la obligatoria, que trata de las normas inherentes a diferentes tradiciones; 3) la de las tendencias y necesidades del ser humano que necesitan ser satisfechas a través de su acción; 4) la ambiental-social, que aborda los aspectos sociales y ambientales de la acción; 5) la de los valores y papeles, que trata de las exigencias relativas a los padrones de nuestro actuar en los roles sociales.

Como se puede percibir, los distintos modelos de teología prácti$\mathrm{ca} /$ pastoral también tienen maneras diversas de relacionarse con otras ciencias, aparte de conferirles estatutos diferenciados a las mismas en la lectura teológica de la realidad y en el hacer teológico como tal. En cada uno de estos modelos hay una reflexión de tipo fundamental, que establece los principios y criterios epistemológicos y hermenéuticos propios a cada uno, y una reflexión de tipo operacional, que ofrece aplicaciones o implicaciones específicas a los respectivos modelos. Tres grandes paradigmas del pensar contemporáneo pueden ser percibidos como fundamentos teóricos de la reflexión fundamental de cada uno de estos modelos: el empírico/pragmático, de corte anglosajón; el ético/crítico, marcado por los teóricos de la Escuela de Frankfurt; y el hermenéutico/ crítico, determinado por el giro hermenéutico del pensar filosófico.

Podríamos preguntarnos hasta qué punto, en una época marcada por la desconfianza con relación a los saberes pragmático-técnicos-responsables por la instrumentalización del mundo de la vida, amenazándolo de destrucción, según muchos-, o en una cultura que pone en cuestión 
el «pensamiento fuerte» - en beneficio de los fragmentos del presente, donde el individuo, su gusto y deseo son lo que cuentan, según otros-, tales modelos pueden ayudar a pensar teológicamente la fe y la acción cristiana. Sin lugar a duda, continúan siendo importantes en la actualidad y pueden iluminar el hacer teológico, pero la mudanza de época en que vivimos pone en crisis todas las certezas y modelos. ¿Todavía vale la pena recurrir a tales modelos en teología? Toda crisis puede revelarse rica en nuevas posibilidades. La actual no es distinta. Por eso, más que responder a las preguntas supraseñaladas, nos gustaría, en esta última parte, proponer algunos elementos que deben ser tomados en cuenta en la lectura teológica de la realidad hodierna, fundamentales en el quehacer teológico en general y al quehacer de la teología práctica/pastoral en particular, indicando a qué saberes deberán recurrir.

III. ¿A QUÉ SABERES RECURRIR EN LA LECTURA TEOLÓGICA DEL PRESENTE?

No se trata aquí de proponer un nuevo modelo para hacer teología en general o para la teología práctica/pastoral en particular, modelo que sería alternativo a los surgidos de los paradigmas subyacentes a los principales modelos hoy vigentes, que parecen en crisis en la cultura contemporánea. Proponemos una reflexión a partir de los elementos que juzgamos indispensables a todo hacer teológico. Los tomamos a la "pequeña ética de Ricoeur», definida en los siguientes términos: "perspectiva de una vida buena con y para el otro en instituciones justas» ${ }^{35}$. La vida buena, según él, tiene que ver con la "estima de sí» y el "cuidado del otro» en «instituciones justas». Por supuesto estos elementos tienen que ser tomados desde la perspectiva de la reflexión teológica. Esta no se da solamente al interior de la Iglesia y no visa solamente a la comunidad de los creyentes, pero, como lo muestra David Tracy, tiene que tener en cuenta también otros dos públicos u interlocutores, a saber la universidad y la sociedad ${ }^{36}$. Veamos qué significado e implicaciones tienen esas ideas para la teología.

La estima de sí

Según Ricoeur, la estima de sí tiene que ver con el sujeto de la acción, que es el sujeto capaz de intencionalidad, capaz de un actuar reflexio-

35 Ver: P. Ricoeur, Soi-même comme un autre (Paris 1990).

36 D. TRACY, The analogical imagination: Christian theology and the culture of pluralism (New York 2000). 
nado, capaz de iniciativa y decisión. Es apreciando nuestras acciones, dice él, que nos apreciamos a nosotros mismos como sus autores, responsables de ellas por lo tanto, y no apenas como simples fuerzas de la naturaleza.

El nivel de la acción se despliega jerárquicamente, desde el ámbito de las prácticas -que se dan en el dominio de la profesión, del arte y del juego-; pasan por el ámbito de los planes de vida -que tienen que ver con la vida familiar, profesional, asociativa, política, etc.-; y culminan en la unidad narrativa de una vida -que corresponde a la vida reunida en una identidad narrativa que posee una cualificación ética-. Para el filósofo francés, en todos estos ámbitos de la acción recurrimos a la capacidad de la imaginación. Esta ejerce en nosotros la función general del "posible práctico ${ }^{37}$. De hecho, antes de escoger algo imaginamos un proyecto de acción, el cual prevé por su vez el ensayo de distintos cursos del actuar y sus prácticas posibles. La imaginación interviene en todos esos pasos para esclarecer las motivaciones de la acción, tornando posible el espacio de la comparación y llevando, finalmente, a la decisión. Los modelos de vida buena y realizada, propuestos por el arte de narrar, pueden iluminar la acción. En este sentido, la imaginación ética se alimenta de la imaginación narrativa ${ }^{38}$.

La estima de sí y los ámbitos implicados en ella apuntan para algunos datos importantes de la cultura actual, marcada por la afirmación exacerbada del individuo, y que hay que tomar en cuenta en el quehacer teológico. El individuo en cuestión se entiende como sujeto de derechos y fuente de deseos. La dimensión ética, presente en la propuesta de Ricoeur para pensar la "estima de sí», no siempre se encuentra en esta afirmación. Aun así, la teología no puede ignorar al individuo. Ella tiene que recurrir a la capacidad que sus textos fundacionales tienen para despertar en él la imaginación y ofrecerle otros mundos posibles. Pueden contribuir en este proceso las ciencias que exploran la imaginación y la creatividad, y que tienen que ver con la estética, sean ellas procedentes del campo poético-literario o del campo artístico y comunicacional. La estética no se agota en sí misma y el camino de la belleza puede conducir al de la bondad. Otro ámbito que atrae al individuo hoy día es el de la mística, objeto de interés de varias ciencias humanas, sobre todo de las

37 P. Ricoeur, Du texte à la action. Essais d’herméneutique II. (Paris 1986) 225.

38 P. Ricoeur, Soi-même comme un autre, 194-195. 
ciencias de la religión. Las prácticas, los planes de vida y la unidad narrativa de una vida son vastos campos a explorar, sea en la comprensión del propio individuo y de su actuar, sea en lo que ofrece el pensar teológico. Entre las prácticas eclesiales, sin duda las del campo litúrgico -espacio y tiempo de celebración, canto, simbólica etc.- traen potencialidades que pueden ser redescubiertas. Lo mismo se puede decir de los varios itinerarios recorridos por la mística, tan al gusto de muchos contemporáneos, que van desde la peregrinación hasta los distintos itinerarios personales, con sus ejercicios, prácticas, textos espirituales, etc.

El cuidado del otro

El segundo elemento de la ética de Ricoeur, el cuidado del otro, describe ese movimiento de sí hacia el otro y hace que yo quiera vivir una vida buena con y para el otro. El cuidado, dice el filósofo francés, responde a la interpelación del sí por el otro, tan bien analizada por Levinas, que insiste en la dimensión prescriptiva de tal interpelación. Sin embargo, observa nuestro filósofo, la búsqueda ética más profunda es la de la reciprocidad que instituye al otro como mi semejante y me instituye a mí mismo como el semejante del otro ${ }^{39}$. La amistad es la máxima expresión de esto. La estima de sí posee esta facultad de reconocer en el otro la misma capacidad de actuar intencionalmente, de tomar iniciativas y decisiones en el mundo. El otro, al que yo le digo tú, es también la sede de una estima de sí a la cual mi cuidado responde. En esto sentido, el amor a sí y el amor al otro se encuentran sin ninguna prioridad. Descubrimos, dice Ricoeur, que el cuidado ya estaba en germen en la estima de sí. Pero lo que el cuidado añade a la estima de sí sin quitarle nada, «es esta idea de mutualidad en el intercambio entre humanos que se estiman cada uno a sí mismo» ${ }^{40}$. Según el filósofo francés, la imaginación juega también aquí un papel importante, pues ella es la capacidad de ponernos en el lugar del otro "en imaginación y simpatía».

El tema del cuidado es eminentemente ético. Curiosamente, la época que más exacerba la afirmación del individuo es también la que más habla de la alteridad y del cuidado. En parte, esto puede ser síntoma de una ausencia y la inflación de las palabras engaño retórico. No obstante, ese síntoma puede también ser leído como llamado a lo que nos falta, sea

\footnotetext{
39 P. Ricoeur, Soi-même comme un autre, 220.

40 P. Ricoeur, Soi-même comme un autre, 220.
} 
porque la estima de sí no se traduce en cuidado, lo que tal vez significa que ella no existe de hecho, o porque la soledad del sí no le basta sino que necesita al otro que lo reconozca y lo interpele a cuidarlo o a ser su amigo. La literatura, la historiografía, la antropología, la sociología, la historia comparada de las religiones y otras ciencias humanas dieron grandes contribuciones para conocer al otro en su diferencia en las últimas décadas y han sido importantes para la teología cristiana. Esta, por su vez, tuvo un papel importante en la historia de la humanidad en la afirmación del otro. Aparte de continuar profundizando en esta dimensión en términos de teología fundamental, los campos de la ética y de la bioética (y genética) son lugares importantes a explorar. La teología podrá ofrecer ahí una contribución importante, ya que en esos campos se levantan hoy cuestiones de extrema urgencia. Lo mismo se puede decir del área de la antropología, donde se levantan cuestiones fundamentales, como las de diferencia y opción sexual, las de las relaciones cuerpo y mente, cuerpo y alma, etc.

El otro propuesto por la imaginación bíblica y teológica como rostro por excelencia a ser cuidado sigue siendo el rostro del pobre, sean los pobres reales a los cuales Jesús mostró su proximidad, acogida y cuidado, y que nos siguen interpelando hoy día bajo tantos nuevos rostros -apuntados por los obispos de América Latina en Puebla y en Aparecida-, sea el «hombre de los dolores» que desde la cruz nos llama a identificarnos con él, no en contemplación pasiva, sino en un real gesto de compasión.

Las instituciones justas

El tercer elemento de la reflexión de Ricoeur introduce, con el tema de la institución, una relación al otro que no se puede reducir a la relación de solicitud. El otro no es más el otro de la amistad o el otro que llama el cuidado de mi solicitud, sino más bien el cada uno de una distribución justa $^{41}$. La justicia se extiende más allá de la proximidad del reconocimiento mutuo. Eso supone que el vivir bien y la vida realizada no se limitan a las relaciones interpersonales, pero se extienden a la existencia y funcionamiento de las instituciones. Además de esto, la justicia presenta una búsqueda de igualdad que no es idéntica a la amistad. Según Ricoeur, tratase de una equidad en la distribución de los roles, de las tareas y de los desventajas presentes en toda institución.

41 P. Ricoeur, Soi-même comme un autre, 227-236. 
Según Ricoeur, la institución se caracteriza primeramente por un ethos y por costumbres comunes, más que por reglas constringentes. Eso le permite mostrar que en ese nivel la justicia aún está vinculada al deseo del buen vivir y a la solicitud por el otro, antes de ser una ley que obliga. La institución tiene también que ver con el poder y con la acción política. En ella se pone la cuestión de la justicia, que tiene sus raíces en el terreno inmemorial y religioso de las culturas, como lo muestran los textos de la tragedia griega, los relatos bíblicos y las grandes obras de literatura de la humanidad. Antes de formalizarse bajo la forma de leyes y argumentos jurídicos, la justicia es un sentido de lo justo y de lo injusto, que nasce de nuestras experiencias y de nuestras herencias culturales. La imaginación también interfiere en el imaginario social, bajo la forma de la ideología y de la utopía, la primera funcionando como justificación de la sociedad y la segunda como su subversión. Las dos son importantes, todavía, pues la sociedad necesita de un ideario que la haga subsistir en el tiempo -ideología-, u la provoque a transformar lo que no corresponde a sus ideales y deseos de justicia-utopía.

Los modelos de teología crítica, a los cuales nos referimos en este texto, se inspiran mucho de ese elemento fundamental de la existencia humana que es la búsqueda de justicia. Fue él quien dio a este tipo de teología pertinencia y relevancia en las sociedades contemporáneas. Él sigue por eso esencial al quehacer teológico, pues ayuda a los cristianos a vivir la dimensión profética de sus acciones en lo económico, en lo político, en lo cultural, en lo ecológico y en lo ético, ya que les ofrece el imaginario utópico del Reino de Dios para refigurar tales acciones. Para eso, la teología tiene que seguir recurriendo a los instrumentales de las ciencias sociales, pues estas le ayudan a una lectura más aguda de esos distintos ámbitos de la realidad. Como subrayamos, ese aspecto hoy día parece menos valorado en una sociedad de individuos. La teología, sin absolutizarla, puede todavía seguir recordando que el humano no se reduce a la estima de sí, ni al cuidado del otro, pero vive con otros en un mundo que es llamado, según la fe cristiana, a tornarse Reino de Dios, la casa común en donde todos puedan sentirse y de hecho ser hijos e hijas de Dios, hermanos y hermanas en Cristo, realmente configurados a su plenitud de humanidad, llegando por eso mismo a humanizarse realmente. 


\section{Concluyendo}

El camino recorrido nos mostró que desde sus comienzos, en el siglo XVIII, hasta nuestros días, la teología práctica/pastoral buscó el auxilio o el diálogo con otros saberes. Su búsqueda fue motivada, ora por el intento de alcanzar lo que la modernidad entendía como científico, ora por el deseo de alcanzar realmente cierta eficacia y pertinencia junto a los destinatarios de la misión de las iglesias. Algunos de los proyectos elaborados mantuvieran una relación meramente instrumental con los saberes a los cuales recorrían, otros intentaron transformar el quehacer teológico. Cada proyecto respondía todavía a los desafíos y cuestionamientos de su época, pues la teología práctica/pastoral, más que cualquier otra teología, es situada y llamada a rehacerse en el nuevo contexto en el cual se encuentran los cristianos y la iglesia. Su tarea es justamente tornar presente el testimonio del Dios volcado hacia la humanidad para que esta logre humanizarse en plenitud. En este sentido, es una teología del testimonio, invitada siempre a rehacerse de nuevo, pues ser cristiano no es algo ya dado, sino una vocación.

Los elementos que creemos esenciales en todo quehacer teológico - estima de sí, cuidado del otro, en instituciones justas-, tienen que tomar cuerpo en la teología práctica/pastoral, sea desde el punto de vista de una reflexión de orden fundamental, sea desde el punto de vista de propuestas concretas, que tornen efectiva la presencia crística en el mundo. Los lugares y públicos del quehacer de la teología práctica/pastoral hoy -la comunidad, la universidad y la sociedad-, nos muestran que el sí, el otro y el cada uno, a los cuales ella tiene que tener en cuenta, es plural, con demandas distintas, exigiendo por eso mismo, saberes diferenciados para poder responder a tales demandas. Todo un campo de invención y de creatividad se abre entonces a la inteligencia de la fe, que puede y tiene que contar con el camino hecho, sin ignorar todavía el que hay que recurrir. Como el testigo, el teólogo práctico/pastoral, es de nuevo puesto en el camino, llamado a ofrecer a los hombres y mujeres de su tiempo razones para creer, esperar y amar. 
Resumen: Tras un breve recurrido histórico del lugar de los otros saberes en la teología práctica/pastoral, el presente artículo hace un análisis de cómo estos saberes se encuentran hoy día en los principales modelos de teología práctica/pastoral, a saber: 1) las teologías prácticas empíricas, más presentes en los países anglosajones, que dialogan mucho con la sicología y la pedagogía; 2) las teologías prácticas críticas, como son las teologías política y de la liberación, que hacen de la praxis la categoría central del quehacer teológico y entran en un diálogo estrecho sobre todo con la sociología, la economía y las ciencias políticas; 3) las teologías prácticas/pastorales fundamentales, propuesta por Browning, que intentan dialogar sobre todo con la filosofía hermenéutica. En un tercer momento, partiendo de tres categorías de la ética de Paul Ricoeur, es decir, la estima de sí, el cuidado el otro y la búsqueda de instituciones justas, el texto propone pensar el quehacer de la teología práctica/ pastoral alrededor de esas categorías, mostrando a qué saberes recurrir.

Palabras clave: Teología práctica/pastoral; otros saberes; ciencias humanas

Abstract: After a brief historical review of the role of other knowledges in practical/pastoral theology, this article analyzes how these knowledges are found today in the main models of practical/pastoral theology, namely: 1) empirical practical theologies, more present in Anglo-Saxon countries, which are often in dialogue with psychology and pedagogy; 2) critical practical theologies, such as political and liberation theologies, which make praxis the central category of the theological task and that are in close dialogue mainly with sociology, economics and political science; 3) fundamental practical/pastoral theologies, proposed by Browning, which attempt to dialogue principally with hermeneutic philosophy. In a third stage, based on Paul Ricoeur's three ethical categories, that is to say, self-esteem, caring for others and the pursuit of just institutions, the text suggests thinking about the practical/pastoral theological task surrounding these categories, presenting which knowledges to resort to.

Keywords: Practical/pastoral theology; other knowledges, human sciences. 